\title{
Anticancer Potential of Citrus Juices and Their Extracts: A Systematic Review of Both Preclinical and Clinical Studies
}

\author{
Santa Cirmi ${ }^{1,2 \dagger}$, Alessandro Maugeri ${ }^{1,2 \dagger}$, Nadia Ferlazzo ${ }^{1}$, Sebastiano Gangemi ${ }^{3}$, \\ Gioacchino Calapai ${ }^{4}$, Udo Schumacher ${ }^{5}$ and Michele Navarra ${ }^{1 *}$ \\ ${ }^{1}$ Department of Chemical, Biological, Pharmaceutical and Environmental Sciences, University of Messina, Messina, Italy, \\ ${ }^{2}$ Prof. Antonio Imbesi Foundation, Messina, Italy, ${ }^{3}$ Department of Clinical and Experimental Medicine, University of Messina, \\ Messina, Italy and Institute of Applied Sciences and Intelligent Systems, National Research Council, Pozzuoli, Italy, \\ ${ }^{4}$ Department of Biomedical and Dental Sciences and Morphofunctional Imaging, University of Messina, Messina, Italy, \\ ${ }^{5}$ Department of Anatomy and Experimental Morphology, University Medical Center Hamburg-Eppendorf, Hamburg, Germany
}

\section{OPEN ACCESS}

Edited by:

Thomas Efferth,

Johannes Gutenberg-Universität

Mainz, Germany

Reviewed by:

Francesca Borrelli,

University of Naples Federico II, Italy

Olga Palomino,

Facultad de Farmacia, Universidad Complutense de Madrid, Spain

*Correspondence:

Michele Navarra

mnavarra@unime.it

${ }^{\dagger}$ These authors have contributed equally to this work and share the first authorship.

Specialty section: This article was submitted to

Ethnopharmacology,

a section of the journal

Frontiers in Pharmacology

Received: 24 April 2017 Accepted: 14 June 2017

Published: 30 June 2017

Citation:

Cirmi S, Maugeri A, Ferlazzo N Gangemi S, Calapai G, Schumacher U and Navarra M (2017) Anticancer Potential of Citrus Juices and Their Extracts: A Systematic Review of Both Preclinical and Clinical

Studies. Front. Pharmacol. 8:420. doi: 10.3389/fphar.2017.00420
Background: During the last decades, a huge body of evidence has been accumulated suggesting that Citrus fruits and their juices might have a role in preventing many diseases including cancer.

Objective: To summarize the numerous evidences on the potential of Citrus juices and their extracts as anticancer agents.

Data sources: A systematic review of articles written in English using MEDLINE (1946present), EMBASE (1974-present) and Web of Sciences (1970-present) was performed independently by two reviewers. Search terms included Citrus, Citrus aurantifolia, Citrus sinensis, Citrus paradisi, Citrus fruits, Citrus fruits extract, cancer, neoplasm, neoplasia, tumor, metastasis, carcinogenesis, proliferation. The last search was performed on March 16th, 2017.

Study selection: Study selection and systematic review were carried out in accordance with the Preferred Reporting Items for Systematic Reviews and Meta-Analyses (PRISMA) statement. Prior to the beginning of the review, Authors defined a checklist for inclusion criteria, thus including articles which meet the following: (i) published on peer-reviewed scientific journals; (ii) Citrus juice used alone; (iii) extracts derived from Citrus juice; (iii) for preclinical studies, an exposure time to Citrus juices and their extracts more than $24 \mathrm{~h}$. Reviews, meta-analyses, conference abstracts and book chapters were excluded.

Data extraction: Three reviewers independently performed the extraction of articles.

Data synthesis: 22 papers met our inclusion criteria and were eligible for inclusion in the final review. According to the kind of study, the selected ones were further divided in preclinical $(n=20)$ and observational $(n=2)$ studies.

Conclusion: The studies discussed in this review strongly corroborate the role of Citrus juices and their derivatives as potential resource against cancer.

Keywords: Citrus juice, cancer, proliferation, alternative medicine, in vitro, in vivo, humans, systematic review 


\section{INTRODUCTION}

Cancer is a major health problem in the developed world, just after aging-related cardiovascular disease, with 14 million cases worldwide and 8.2 million of deceases just in $2012^{1}$. This cancer epidemic has a considerable social impact with high socioeconomic costs. The fight against cancer is realized by developing innovative drugs and novel therapeutic strategies aimed to cure the disease, as well as to prevent it.

Over the recent decades, we witnessed a return to natural remedies to prevent or treat a large number of degenerative diseases (Paterniti et al., 2014; Cirmi et al., 2016c; Ferlazzo et al., 2016a). Frequently, they are employed when minor health problems occur, however they can even be used as co-adjuvants for synthetic drugs in major health problems. Indeed, natural drugs, supplements and functional foods raised interest in the general population, which more often prefers to use these remedies rather than synthetic ones. This choice is preferred because they are easier to use and exert fewer side effects, thus contributing to increase patients' compliance. Hence, up to $80 \%$ of people is using natural remedies worldwide. However, they should not be used empirically, but rather it is greatly important that their effectiveness is evaluated by clinical studies. This thesis led the scientific community to revise the use of some natural medicines employed for decades whom effectiveness has been recently placed in doubt (Tacklind et al., 2012; Micali et al., 2014; Semba et al., 2014).

Another approach to prevent degenerative diseases is following a combination of a healthy life style and diet habits, employing "food as medicines" (Ullah and Khan, 2008). For instance, it has been suggested that high dietary intake of vegetables and fruits (>400 g/day) could prevent at least $20 \%$ of all cancer cases (Amin et al., 2009; Gullett et al., 2010). This preventive effect is predominantly exerted by biologically active molecules like flavonoids which are capable of interacting with specific targets that play a role in the generation and progression of cancer (Ravishankar et al., 2013). Citrus fruits (CF) are the most eaten fruits in the Mediterranean diet that it is known to reduce the risk of degenerative diseases, including cancer (Giacosa et al., 2013). CF represent one of the most important diet sources of flavonoids (Kozlowska and Szostak-Wegierek, 2014) whose benefits are due to many biological properties, among

\footnotetext{
${ }^{1}$ (IARC) IAfRoC. (2014). World Cancer Report 2014.
}

Abbreviations: 4-NQO, 4-Nitroquinoline-1-Oxide; AOM, azoxymethane; Bax, bcl-2-like protein 4; Bcl-2, B-cell lymphoma 2; BEO, bergamot essential oil; $\mathrm{BJ}$, bergamot juice; BJe, bergamot juice extract; CF, Citrus fruits; CJ, citron juice; COX-2, cyclooxygenase 2; DMBA, 7,12-Dimethylbenz[a] anthracene; FAK, focal adhesion kinase; $\mathrm{H}_{2} \mathrm{O}_{2}$, hydrogen peroxide; IL1- $\beta$, interleukin 1 beta; IL6, interleukin 6; iNOS, inducible nitric oxide synthase; LiJ, lime juice; MAPK, mitogen-activated protein kinase; $\mathrm{MJ}$, mandarin juice; $\mathrm{MJe}$, mandarin juice extract; MMP, mitochondrial membrane potential; MMP-2, matrix metalloproteinase-2; MnSOD, manganese-dependent superoxide dismutase; MPO, myeloperoxidase; NF-kB, nuclear factor kappa B; NKK, 4-(methylnitrosamino)-1-(3-pyridyl)-1butanone; Nrf2, NF-E2-related factor 2; OJ, orange juice; OJe, orange juice extract; PAR, poly ADP-ribose; PhIP, 2-amino-1-methyl-6-phenylimidazo[4,5-b]pyridine; PRISMA, Preferred Reporting Items for Systematic Reviews and Meta-Analyses; ROS, reactive oxygen species; SCID, severe combined immunodeficiency; TNF- $\alpha$, tumor necrosis factor; TRAIL, TNF-related apoptosis-inducing ligand.

which the well-known antioxidant activity and the modulation of intracellular key pathways involved in degenerative processes leading to chronic pathologies such as cancer. In particular, dietary flavonoids interfere with carcinogen activation, stimulate carcinogen detoxification, scavenge free radical species, control cell-cycle progression, induce apoptosis, inhibit cell proliferation, oncogene activity, angiogenesis and metastasis as well as inhibit hormones or growth-factor activity (Clere et al., 2011).

The objective of our systematic review is to summarize and critically discuss the numerous evidences on the anticancer properties of Citrus juices and their extracts.

\section{METHODS \\ Search Strategy}

Two reviewers (SC and $\mathrm{MN}$ ) independently performed a bibliographic research in the following electronic databases: MEDLINE (1946-present), EMBASE (1974-present), and Web of Sciences (1970-present). In order to retrieve all relevant papers, no limit was placed on search time frame. The last search was performed on March 16th, 2017.

The databases were searched for relevant studies that included at least one keyword or Medical Subject Heading from each of the following: (i) Citrus, Citrus aurantifolia, Citrus sinensis, Citrus paradisi, Citrus fruits, Citrus fruits extract; (ii) cancer, neoplasm, neoplasia, tumor, metastasis, carcinogenesis, proliferation. The search was also limited to English language. An example of full electronic search strategy for EMBASE is provided in Table $\mathbf{1}$. Citations, titles and abstracts were exported into Endnote X5.

Study selection and systematic review were performed in accordance with the Preferred Reporting Items for Systematic Reviews and Meta-Analyses (PRISMA) statement (Liberati et al., 2009). Prior to the beginning of the review, Authors defined a checklist for inclusion criteria, thus including articles that meet the following: (i) published on peer-reviewed scientific journals; (ii) Citrus juice used alone; (iii) extracts derived from Citrus juice; (iii) for preclinical studies, an exposure time to Citrus juices and their extracts more than $24 \mathrm{~h}$. Consequently, we excluded: (i) studies performed using preparations derived from other fruits or other parts of the CF (i.e., peel, seeds, whole fruit, etc.); (ii) studies in which the Citrus juices were used in combination with other fruits or juices; (iii) studies carried out with isolated

TABLE 1 | Full electronic search strategy for EMBASE.

\section{Search strategy for EMBASE}

Limit applied: "English"

1. Citrus
2. Citrus fruits
3. Citrus fruits extract
4. 1 OR 2 OR 3
5. cancer
6. neoplasm
7. neoplasia

1. Citrus

2. Citrus fruits

3. Citrus fruits extract

4. 1 OR 2 OR 3

5. cancer

7. neoplasia
8. tumor
9. metastasis
10. carcinogenesis
11. proliferation
12. 5 OR 6 OR 7 OR 8 OR 9 OR 10 OR 11 13. 4 AND 12 
molecules extracted from Citrus juices. We also excluded reviews, systematic reviews, meta-analyses, letters, personal opinions, conference abstracts and book chapters.

Potentially relevant articles were screened independently by three reviewers (SC, AM, and $\mathrm{MN}$ ), initially by abstract and then by full text. Two reviewers had previous experience with systematic review (SC and MN). Disagreements among reviewers were resolved by consensus discussions.

\section{RESULTS}

\section{Study Selection}

The initial electronic databases search resulted in 3,135 articles that were reduced to 2120 when duplicates were discarded. Of these latter, 31 articles were selected for detailed review, with only 22 ones eligible for inclusion in the final review process. Figure 1 shows the flow of papers through the review. According to the kind of study, the selected ones were further divided in preclinical $(n=20)$ and observational clinical studies $(n=2)$. Tables 2-4 summarize the different variables of all studies taken into account. Articles excluded because they were conference abstracts or book chapters were $n=197$. Records excluded for title and abstract were $n=1892$. Articles excluded after full text review were $n=9$ : two because combined Citrus juice with CF, one because tested the anti-proliferative effects of a Citrus juice on non-malignant cells, one because cells exposure time to a Citrus juice was less than $24 \mathrm{~h}$ and five because did not test Citrus juices or their extracts.

\section{Citrus Juices and Their Extracts in Cancer: Focus on Preclinical Studies}

Citrus fruits (CF) originated from tropical and sub-tropical areas of South-East Asia and were imported into Europe during the times of the Roman Empire. In Mediterranean basin, CF found favorable climatic conditions leading to extensive cultivation and the origin of many new hybrids (Duarte et al., 2016). Hence, Citrus taxonomy is quite controversial, so that there are different attempts to classify this Rutaceae family (Swingle and Reece, 1967; Tanaka, 1977; Mabberley, 1997). According to recent taxonomy, there are three ancestral taxa: Citrus maxima (pomelos), Citrus reticulata (mandarins), and Citrus medica (citrons) (Garcia-Lor et al., 2013). CF exerts many beneficial effects that improve human health, including mainly anti-oxidant, anti-inflammatory, anti-microbial and anticancer effects, as well as protection against cardiovascular and nervous system injury (Lv et al., 2015; Mandalari et al., 2017). As recently stated by Cirmi and co-workers, an impressive number of preclinical studies explored the anticancer activity of Citrus flavonoids as single compounds (Cirmi et al., 2016b). Conversely, limited investigations tested the potential of Citrus juices or their extracts against cancer.

In this systematic review, we included and discussed twenty preclinical studies in which Citrus juices or their extracts were used as anticancer agents. In particular, twelve papers evaluated the effect of Citrus juices in in vitro experimental models, and eight in in vivo ones.
Citrus sinensis (orange) is a small tree originated in China and then imported to Europe between sixteenth and seventeenth century by Portuguese expeditions (Ferrão, 1979). It is described as a hybrid between Citrus maxima (pomelo) and Citrus reticulata (mandarin). Orange juice $(\mathrm{OJ})$ is one of the most consumed among other CF juices worldwide, and even one of the most studied regarding its health benefits. Indeed, it is well known its antioxidant property that is due to its content of both Vitamin C and flavonoids (Constans et al., 2015). In this regard, recently we studied the antioxidant activity of an extract from orange juice (OJe) rich in flavonoids in both cell-free and cell-based experimental models. In particular, we showed its capability of preventing oxidative stress induced by hydrogen peroxide $\left(\mathrm{H}_{2} \mathrm{O}_{2}\right)$ in human lung epithelial A549 cells, diminishing reactive oxygen species (ROS) generation and membrane lipid peroxidation, as well as enhancing mitochondrial functionality and averting DNA-oxidative damage (Ferlazzo et al., 2015). Moreover, we demonstrated the ironchelating activity exerted by OJe in $\mathrm{Fe}_{2} \mathrm{SO}_{4}$-exposed A549 cells and its induction of the antioxidant catalase, thus stopping oxidative injury induced by iron (Ferlazzo et al., 2016c). We further studied the antioxidant and anti-inflammatory activity of OJe through an animal model resembling colitis (Fusco et al., 2017) in which it counteracted cytokine generation, nuclear factor kappa B (NF-kB) activation, nitrotyrosine and poly ADPribose (PAR) formation, as well as enhanced myeloperoxidase (MPO) activity, increased manganese-dependent superoxide dismutase (MnSOD) expression and modulated both pro- and anti-apoptotic factors. Finally, it has been demonstrated that both OJ and OJe are capable of reducing cardiovascular risks (Buscemi et al., 2012) and exert anti-epileptic effect (Citraro et al., 2016). We found seven preclinical studies on the anticancer activity of OJ matching the eligibility criteria of our review. Among these, four have been investigated in in vitro experimental models (Kawaii et al., 1999; Camarda et al., 2007; FernandezBedmar et al., 2011; Dourado et al., 2015) and two in animal models (So et al., 1996; Miyagi et al., 2000). Through in vitro study, Kawaii and co-workers screened 34 Citrus juices for their antiproliferative activity on several cancer cell lines (A549, human lung carcinoma; B16 mouse melanoma 4A5; CCRF-HSB-2, T-cell leukemia; TGBC11TKB, human gastric adenocarcinoma) and non-cancer cell line (HUVEC, human umbilical vein endothelial cells; HFK normal human foreskin keratinocytes) (Kawaii et al., 1999). Citrus juices tested included C. bergamia, C. limon, C. grandis, C. paradisi, C. aurantium, C. sinensis, C. nobilis, C. unshiu, C. reticulata, C. tangerine, and $C$. clementina. Although with different strength, all the tested juices showed antiproliferative activity, with the most exerted by C. nobilis (Kawaii et al., 1999). The growth inhibitory effect of both lemon and orange juices was also assessed by Fernández-Bedmar and collaborators on human leukemia HL60 cells, suggesting a stronger activity of lemon rather than orange juice ( $\mathrm{IC}_{50} 1.4$ and $4.4 \%$, respectively) (FernandezBedmar et al., 2011). Moreover, Camarda and co-workers showed the antiproliferative effect of $\mathrm{OJ}$ and some varieties of C. reticulata in human chronic myelogenous leukemia (CML) K562, human breast adenocarcinoma MCF-7 and HL-60 cells 


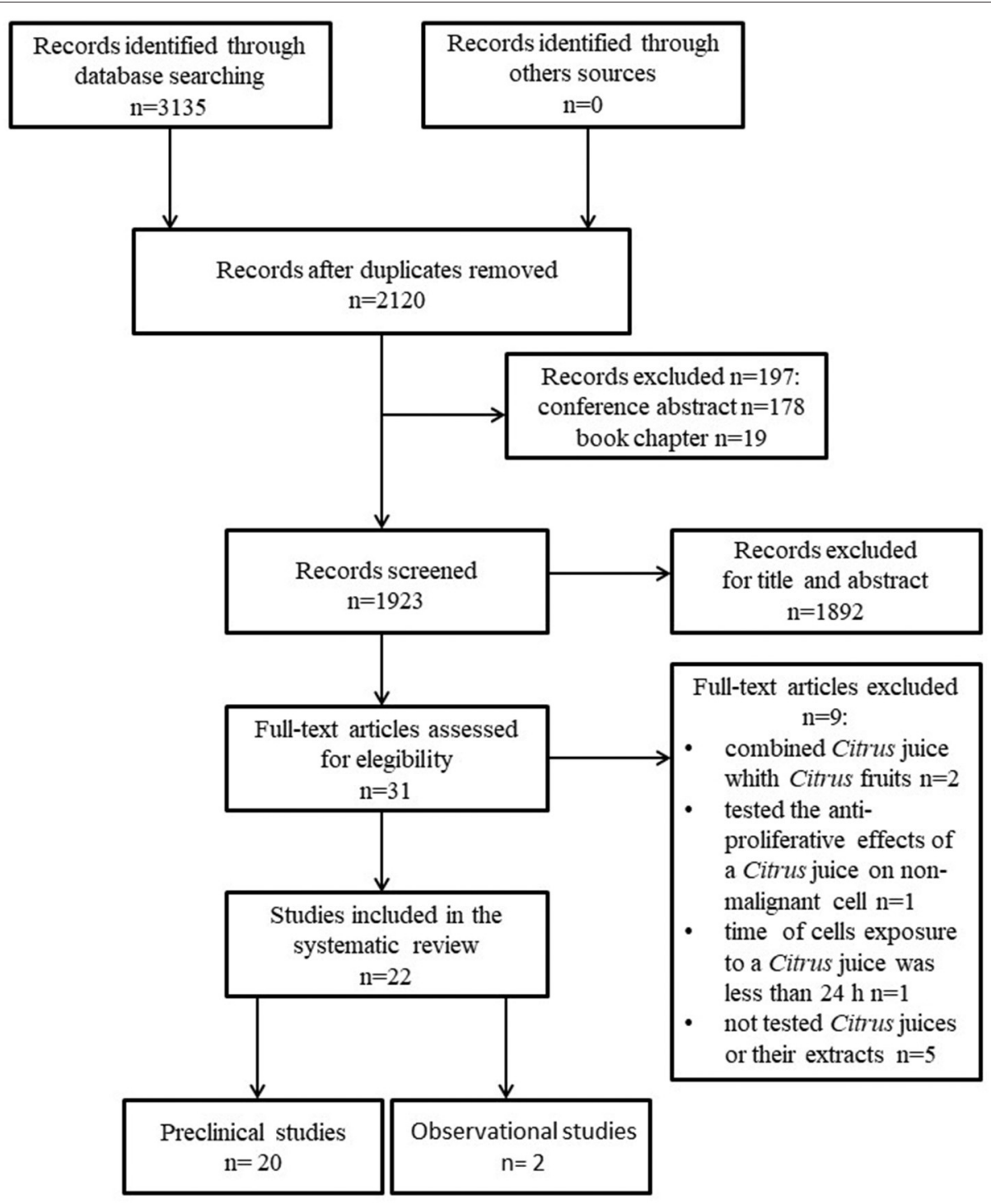

FIGURE 1 | PRISMA flow chart showing the process of literature search and study selection.

(Camarda et al., 2007). Finally, both sweet red-fleshed and blond OJ exert pro-apoptotic effect on Loucy $\mathrm{T}$ acute lymphoblastic leukemia cell line (Dourado et al., 2015). The first study assessing the inhibition of rats' mammary tumor generation caused by 7,12-dimethylbenz[a] anthracene (DMBA) through OJ treatment was performed in 1996 by So et al. (1996). Some years later, Miyagi and collaborators evaluated the capability of $\mathrm{OJ}$ to inhibit azoxymethane (AOM)-induced colon tumor in male rats, indicating that flavonoids and limonoid glucosides are implied in this antitumor activity (Miyagi et al., 2000).

Citrus reticulata (mandarin), originated from South-East China, was imported in Europe just in the nineteenth century, where it was cultivated mainly in Italy and Spain (Zaragoza, 1991), and represents the ancestor of different hybrids and mutants cultivated throughout the world (Scora, 1988;
Mabberley, 2009). The main representative Citrus reticulata varieties in the Mediterranean area are Citrus deliciosa, Citrus unshiu, and Citrus clementina (Tanaka, 1954). Navarro and coworkers have studied the juice of mandarin (MJ) growing in Mediterranean area for its antioxidant activity (Navarro et al., 2011), while Oikeh et al. demonstrated its anti-microbial activity, in some cases, better than other CF (Oikeh et al., 2016). We analyzed five preclinical studies in which MJ was tested for its potential anticancer activity. In particular, we found two in vitro (Camarda et al., 2007; Celano et al., 2015) and three in vivo studies (Tanaka et al., 2000, 2012; Kohno et al., 2001). As mentioned above, OJ, C. clementina and $C$. deliciosa juices exert antiproliferative effect in K562 and HL-60 cells (Camarda et al., 2007). Lately, Celano and co-workers have examined the anticancer properties of a mandarin juice extract rich in 


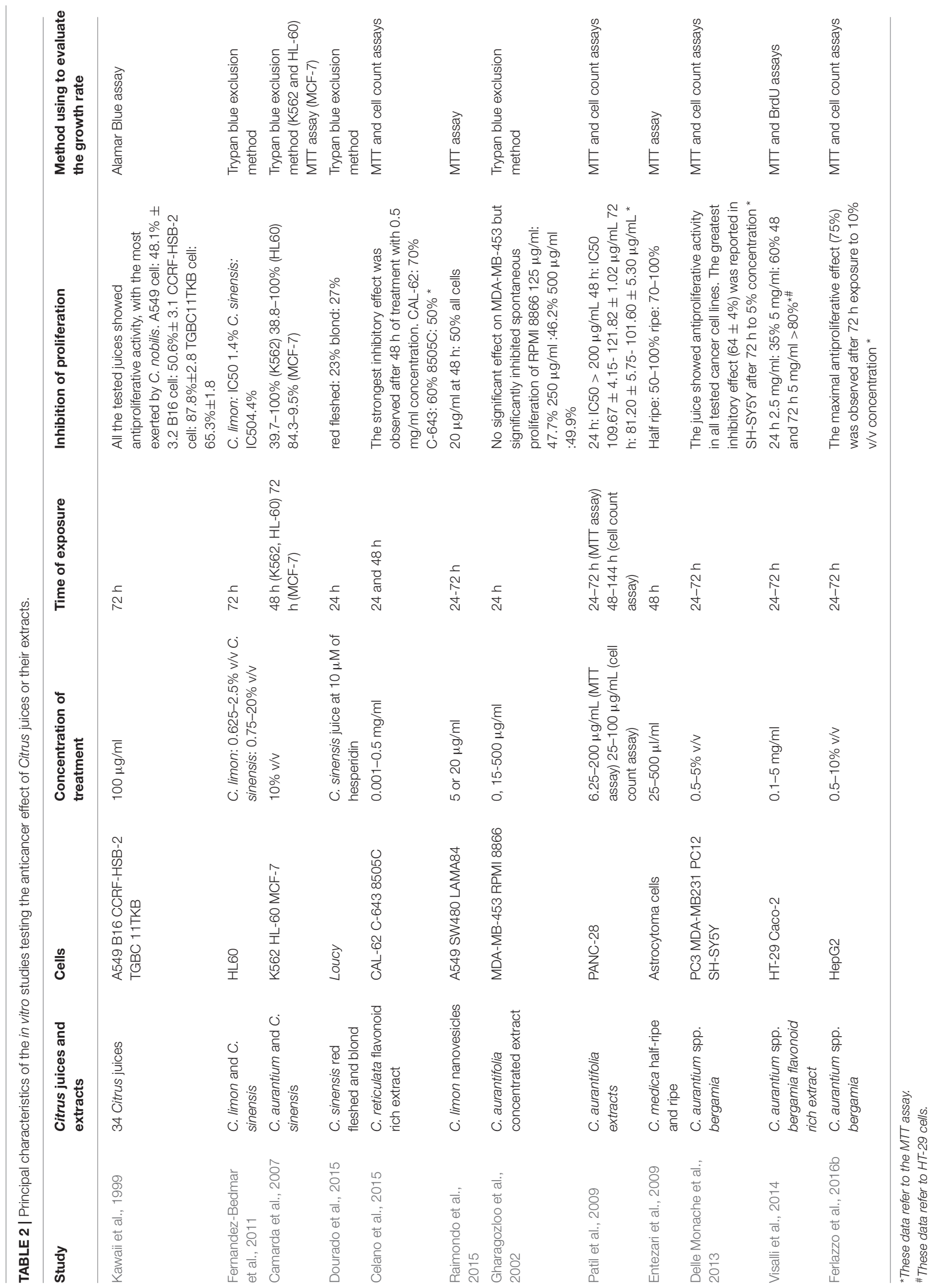




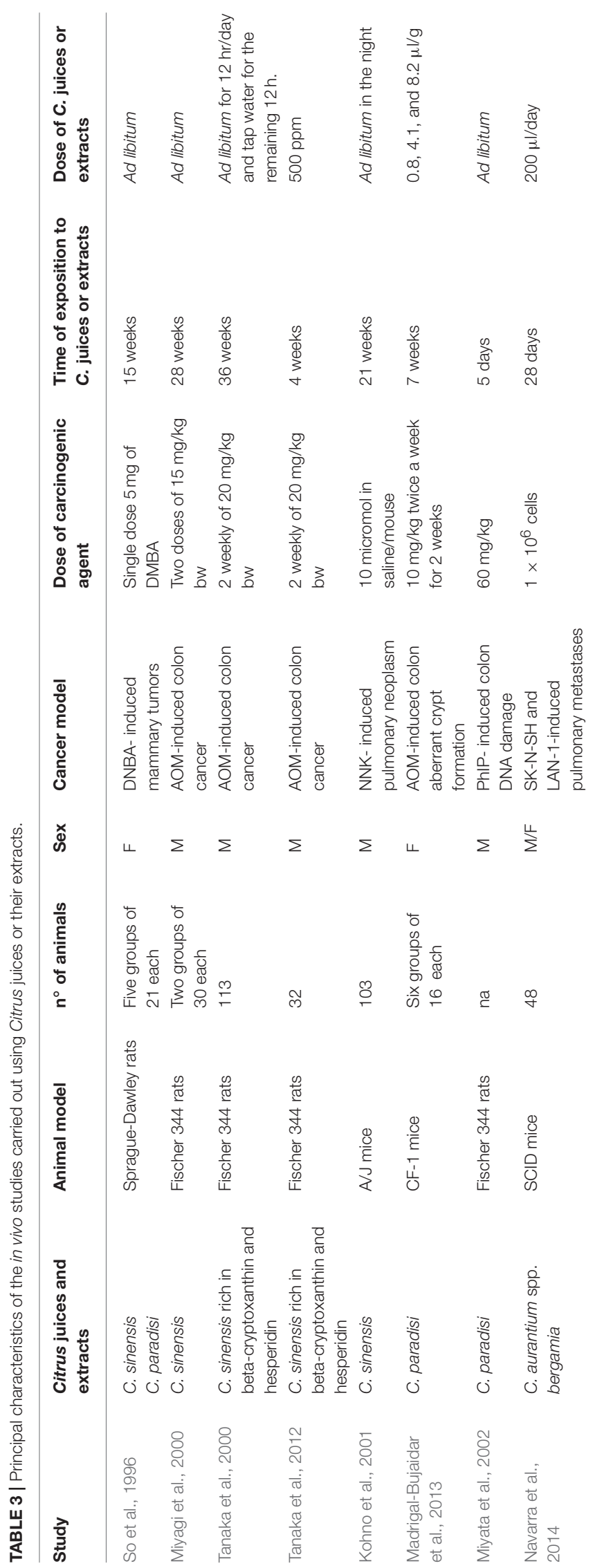

flavonoids (MJe) on three diverse cell lines of human anaplastic thyroid carcinoma (CAL-62, 850C, and C-643). In this study, we demonstrated that MJe blocks cell cycle in G2/M phase, causing a reduction in cell proliferation and an increase in autophagic cell death (Celano et al., 2015). Furthermore, MJe reduced activity of MMP-2, thus decreasing cell migration (Celano et al., 2015). In animal models, Tanaka and collaborators showed the ability of natural MJ and MJs enriched in hesperidin and $\beta$ cryptoxanthin to reduce the AOM-induced colon carcinogenesis in F344 rats (Tanaka et al., 2000). Moreover, the juices cited above were also found to reduce lung neoplasms induced by 4-(methylnitrosamino)-1-(3-pyridyl)-1-butanone (NNK) in A/J mice (Kohno et al., 2001). Finally, these MJs, both natural and enriched, decreased the gene expression of tumor necrosis factor (TNF)- $\alpha$, interleukin (IL)1- $\beta$, IL-6, NF-E2-related factor 2 (Nrf2), COX-2, and iNOS in the tongue and colon of F344 rats subjected to 4-Nitroquinoline-1-Oxide (4-NQO) or AOM to induce carcinogenesis, respectively (Tanaka et al., 2012).

Citrus paradisi (grapefruit) is thought to be a natural hybrid between Citrus maxima and Citrus sinensis that was found in the Caribbean after the discovery of the Americas by Columbus, and then exported to Europe (Barrett and Rhodes, 1976; de Moraes et al., 2007; Ollitrault et al., 2012). Grapefruit juice (GJ) has been extensively studied for its pharmacokinetic interactions with many drugs (Ahmed et al., 2015) and for its antioxidant and anti-inflammatory properties (de la Garza et al., 2015). Only two studies performed in animal models explored the anticancer properties exerted by GJ. MadrigalBujaidar and co-workers showed that GJ suppressed the colon carcinogenesis induced by AOM in mice, by up-regulating apoptosis and reducing both cyclooxygenase-2 (COX-2) and inducible nitric oxide synthases (iNOS) levels, thus suggesting even its anti-inflammatory activity (Madrigal-Bujaidar et al., 2013). Miyata and collaborators demonstrated that GJ also suppresses colon DNA-damage induced by 2-amino-1-methyl-6phenylimidazo[4,5-b]pyridine (PhIP) in F344 male rats, however without identifying the mechanism of action (Miyata et al., 2002).

Citrus limon (lemon) has uncertain origin, even if it is thought to come from South-East Asia, as reported in data from Chinese literature of fifth century BC (Duarte et al., 2016). Then, Arabs brought this Citrus in Europe in twelfth century (Duarte et al., 2016). Citrus limon is known to be a hybrid between Citrus medica, Citrus reticulata, and Citrus maxima (Garcia-Lor et al., 2013). Lemon juice (LeJ) is thought to have, among others, antibacterial (Yang et al., 2013) and anti-oxidant activities (Tounsi et al., 2011). Only the paper by Raimondo et al. met the inclusion criteria of our review and its content is discussed below. Authors demonstrated that the nanovescicles extracted by ultracentrifugating LeJ might induce apoptosis in CML cells by activating TRAIL-mediated cell death (Raimondo et al., 2015).

Citrus aurantifolia (lime) is a tree originated in the tropical Northern Indian area. It was brought by Arabs into Middle East, Northern Africa and Mediterranean Europe, and then Spanish expeditions spread this Citrus in Central and South Americas. It is still widely cultivated in those areas cited above (Khan et al., 2017). Citrus aurantifolia is thought to be a hybrid between $C$. medica and C. micrantha, according to Nicolosi et al. (2000). 
TABLE 4 | Main characteristics of observational studies.

\begin{tabular}{|c|c|c|c|c|c|c|c|}
\hline Study & Citrus juices & Study design & Study population & Primary objective & $\begin{array}{l}\text { Method of dietary } \\
\text { assessment }\end{array}$ & Measures ${ }^{\star}$ & IC95\% \\
\hline $\begin{array}{l}\text { Maserejian } \\
\text { et al., } 2006\end{array}$ & C. sinensis & $\begin{array}{l}\text { Prospective cohort } \\
\text { study }\end{array}$ & $\begin{array}{l}42,311 \text { men aged } 40-75 \\
\text { years when the study began }\end{array}$ & $\begin{array}{l}\text { Evaluate fruit and vegetable } \\
\text { consumption and the } \\
\text { incidence of OPLs }\end{array}$ & $\begin{array}{l}\text { Interview using } \\
\text { 131-item FFQ }\end{array}$ & RR 0.65 & $0.42-0.99$ \\
\hline $\begin{array}{l}\text { Jansen et al., } \\
2011\end{array}$ & $\begin{array}{l}\text { C. sinensis and } \\
\text { C. paradisi }\end{array}$ & $\begin{array}{l}\text { Clinic-based } \\
\text { case-control study }\end{array}$ & $\begin{array}{l}2,473 \text { cases } \\
2,708 \text { controls }\end{array}$ & $\begin{array}{l}\text { Evaluate fruit, vegetable, } \\
\text { fiber, and grain consumption } \\
\text { associations with pancreatic } \\
\text { adenocarcinoma }\end{array}$ & $\begin{array}{l}\text { Interview using } \\
\text { 144-item FFQ }\end{array}$ & OR 0.52 & $0.35-0.79$ \\
\hline
\end{tabular}

${ }^{*}$ Comparing highest to lowest quintiles.

Lime juice (LiJ) is claimed to exert antimicrobial activity on both Gram-positive and Gram-negative bacteria (Aibinu et al., 2006). Only two studies carried out in vitro tested the antiproliferative activity of LiJ (Gharagozloo et al., 2002; Patil et al., 2009). Ghargozloo and co-workers suggested that concentrated LiJ could reduce proliferation of human lymphoblastoid B cell line (RPMI-8866) (Gharagozloo et al., 2002). Furthermore, Patil and collaborators showed that LiJ extracted in different solvents including acetone, chloroform and methanol, modulates the expression of caspase-3, Bax, Bcl-2, and p53, thus inducing apoptosis in Panc-28 pancreatic cancer cell line (Patil et al., 2009).

Citrus medica (citron) is native of Indian region, and is known to be the first CF arrived in the Mediterranean basin, and both Greek and Latin literatures confirmed its presence as food in their diets. Indeed, its name came from "Media" which was the term that referred to Persian area that is where Greek discovered this fruit during Alexander the Great's expeditions (Duarte et al., 2016). As cited previously, C. medica is one of the three ancestral taxa from which every CF drew its origin (Garcia-Lor et al., 2013). We found only one in vitro study in which the antiproliferative activity of citron juice (CJ) was evaluated (Entezari et al., 2009). Authors demonstrated that CJ, at different ripeness stages, showed antiproliferative activity on 1321 human astrocytoma cancer cells. Moreover, they assessed the anti-mutagenicity activity of CJ through Ames test, in which the "half-ripe" CJ resulted stronger than the "ripe" one (Entezari et al., 2009).

Citrus aurantium ssp. bergamia (Risso and Poiteau) also called Citrus bergamia (Risso and Poiteau) or bergamot is thought to be a hybrid between Citrus aurantium L. and either Citrus limon L. (lemon) or Citrus aurantiifolia (lime). Additionally, it may be a mutation of the latter (Rapisarda and Germanò, 2013). It may originate from Canary Islands, Greece or Antilles and then introduced in Spain ("bergamot" can draw its name from the Spanish village "Berga") and, subsequently, in southern Italy. More likely, it may be native of the Calabria region (Italy) where the best worldwide microclimate incentivizes both its plantation and spontaneous growth. Bergamot fruits are mainly used to extract the bergamot essential oil (BEO) mostly used in fragrance, cosmetics, confectionery and food industries. Moreover, BEO possesses antiseptic activities (Cirmi et al., 2016a) and it is used in aromatherapy (Navarra et al., 2015b). It is included in the official Pharmacopoeias of several countries, and its chemical composition has been accurately investigated (Costa et al., 2010). Experimentally, in the last decades, it has been investigated for its potential neuroprotective (Corasaniti et al., 2007) and antitumor activities (Celia et al., 2013; Navarra et al., 2015a). Bergamot juice (BJ), obtained through endocarp squeezing, has only been treated as a waste product of BEO factory chain for long time. Recently, it drew attention because of its hypolipemic and hypoglycaemic activity of its polyphenol fraction (Mollace et al., 2011; Toth et al., 2015; Mannucci et al., 2017). Furthermore, the flavonoid-rich extract from BJ (BJe) possesses both antioxidant and anti-inflammatory activities, as assessed in several in vitro (Risitano et al., 2014; Ferlazzo et al., 2015, 2016c; Curro et al., 2016) and in vivo models (Impellizzeri et al., 2015, 2016). In addition, it exerts antimicrobial effects (Filocamo et al., 2015; Mandalari et al., 2017). Evidence that BJ, BJe or other polyphenol extracts from BJ did not exhibit noticeably signs of systemic toxicity either in animals or in human suggests their valuable risk/benefit ratio (Marino et al., 2015). Four studies focused on the anticancer activity of BJ and BJe, in particular three performed in vitro (Delle Monache et al., 2013; Visalli et al., 2014; Ferlazzo et al., 2016b) and one in vivo (Navarra et al., 2014), and met the inclusion criteria of our systematic review. We have demonstrated that $\mathrm{BJ}$ is able to reduce growth rate in various cancer cell lines through diverse mechanisms. In neuroblastoma cells (SH-SY5Y) BJ caused cell cycle arrest in G1 phase without triggering apoptosis, and induced morphological change that in turn increased the rate of detached cells in different physiological substrates and in endothelial cell monolayer. This peculiarity was due to the ability of BJ to induce impairment of actin filaments and reduce expression of active form of focal adhesion kinase (FAK), thus inhibiting cell adhesiveness and migration (Delle Monache et al., 2013). Conversely, in human hepatocellular carcinoma cells (HepG-2) BJ diminished growth rate through the activation of both extrinsic and intrinsic apoptosis that involved NF- $\mathrm{B}$, p53, and p21 pathways (Ferlazzo et al., 2016b). Furthermore, the BJ-induced reduction of neuroblastoma cells (SK-N-SH and LAN-1) adhesiveness, as assessed in vitro through a laminar flow assay on selectins, might be responsible for the slight inhibition of pulmonary metastasis colonization in an in vivo model of neuroblastoma spontaneous metastases formation in SCID mice (Navarra et al., 2014). We further indicated that the pool of flavonoids presents in BJ is responsible for its anticancer effects, since BJe is able to inhibit the growth 
of HT-29 human colorectal carcinoma cells by induction of apoptosis that can be triggered through different mechanisms depending on the drug concentration (Visalli et al., 2014). Indeed, lower BJe concentrations suppressed MAPK pathways and modulated some proteins linked to the apoptotic machinery, thus inducing arrest of cell cycle and apoptosis. Instead, higher BJe concentrations raised ROS generation leading to loss of mitochondrial membrane potential (MMP) and DNA oxidative damage (Visalli et al., 2014).

\section{Citrus Extracts in Cancer: Focus on Observational Clinical Studies}

In the last 25 years, a large body of evidence, mainly from epidemiological studies, suggests that regular intake of CF could prevent many diseases including cancer. Almost all the studies evaluating the anticancer potential of CF in humans come from case-control studies, but very few of them are performed using just the Citrus juices. We found only two studies that fall within the eligibility criteria of our systematic review. A very interesting prospective cohort study aimed to evaluate the impact of vegetables and fruits consumption and the oral premalignant lesions risk in 42,311 U.S. men was performed in the frame of the "Health Professionals Follow-up Study" (Maserejian et al., 2006). At baseline, participants aged 40-75 years completed detailed questionnaires assessing dietary intake, lifestyle factors, and medical history. Follow-up questionnaires were mailed every 2 years to update exposure information and ascertain newly diagnosed diseases. Authors observed a significant inverse associations with consumption of Citrus fruits and their juices (mainly orange and OJ) indicating 30-40\% lower risk with greater intakes (e.g., Citrus fruit juice quintile 5 vs. quintile $1 \mathrm{RR}$ $=0.65$, IC 95\%: 0.42, 0.99 (Maserejian et al., 2006). More recently, Jansen and co-workers used a clinic-based case-control study to demonstrate the inverse relationship between the consumption of high quantity of fibers, grain, fruits and vegetables and the risk of pancreatic cancer, suggesting that also orange and grapefruit juices might have a role in a pancreatic cancer prevention strategy (Jansen et al., 2011).

\section{DISCUSSION}

For more than a century now, people treated most diseases with synthetic drugs, which have defeated many illnesses and thereby allowed to increase the overall quality of life and its extension. In addition, over the last few decades the advent of biotechnological drugs has further improved the treatment of many chronic diseases. However, the best weapon to fight illnesses is always prevention. In particular, cancer prevention comes from healthy habits, as suggested by Tomasetti and coworkers who claimed that nearly $30-40 \%$ of cancer incidence might be prevented by a proper diet and physical activity in order to maintain appropriate body weight (Tomasetti and Vogelstein, 2015). However, sometimes it may be advisable to assume nutraceuticals, food supplements and natural remedies in order to improve one's natural defenses or to rebalance some loss of nutritional factors important to maintain the health status.
On the contrary, employment of synthetic drugs for preventive purpose is not advisable, mainly because of the side effects that may arise. Indeed, even if natural products are not without risk, generally they are safer than synthetic drugs, have a reasonably effectiveness as well as meet patient's compliance. In this line, about $80 \%$ of people worldwide employs natural remedies to prevent and/or treat several illnesses. Since ancient times, edible plants and their fruits have been the bases of many traditional medicines, continuing to provide humankind with new remedies.

Many natural drugs are single compounds, some of these are implemented in clinical practice to prevent or treat several diseases, including cancer. Taxanes such as paclitaxel and Vinca alkaloids such as vinblastine are examples of active principles derived from plants that are prescribed in cancer therapy. However, our group (Delle Monache et al., 2013; Navarra et al., 2014; Visalli et al., 2014; Cirmi et al., 2016b; Ferlazzo et al., 2016b) and other researchers (Surh, 2003; Liu, 2004; Amin et al., 2009; Efferth and Koch, 2011) hypothesized that a single biologically active molecule, even if used at high concentrations, could not be sufficient in preventing or treating cancer because several different pathways are involved in malignant progression. Therefore, employment of complex mixtures of biologically active substances, such as those present in whole fruits and vegetables, juices or their extracts, increases the chances of success against cancer. The logic behind this hypothesis is: (i) the additive and synergistic actions of their individual components and (ii) their simultaneous modulation of different intracellular targets involved in oncogenesis. Thus, a cocktail of pharmacological actions is playing to induce the anticancer effect (Surh, 2003; Liu, 2004; Amin et al., 2009; Efferth and Koch, 2011; Delle Monache et al., 2013; Navarra et al., 2014; Visalli et al., 2014; Cirmi et al., 2016b; Ferlazzo et al., 2016b). The results of the present systematic review clearly indicate that Citrus juices and their extracts may exert antitumor effects, as suggested by the several studies discussed above that were performed in different in vitro and in vivo experimental models. These indications were strengthened by the data of observational clinical studies presented herein that showed how consumption of Citrus juices (in particular OJ and GJ) is inversely associated with the risk of oral and pancreatic cancer.

It is clearly known that cancer development and chronic inflammation are strictly intertwined each other and that inflammatory cells and released cytokines increase growth and progression of malignancies as well as immunosuppression (Balkwill and Mantovani, 2001). Furthermore, the imbalance of redox and inflammatory pathways between the inside of tumor cells and their surrounding stroma is known to be important in tumorigenesis, invasion and consequent systemic diffusion (Crawford, 2014). Additionally, pathways related to inflammation are constitutive in the majority of cancers. Consequently, the use of antioxidant and anti-inflammatory substances mainly derived from natural origins is highly desirable in the treatment of malignant tumors. Although these substances are not entirely risk-free, they are generally safer than synthetic drugs. Regarding this aspect, we recently showed that BJe possesses both antioxidant (Ferlazzo et al., 2015, 2016c) and anti-inflammatory activities, the latter through in vitro (Risitano 
et al., 2014; Curro et al., 2016) and in vivo studies (Impellizzeri et al., 2015, 2016). We also demonstrated the antioxidant and anti-inflammatory activity of OJe (Ferlazzo et al., 2015, 2016c), as Tarozzi and collaborators claimed for the edible part of orange (Tarozzi et al., 2006), as well as its anti-inflammatory effect (Fusco et al., 2017). These properties corroborate the anticancer activity of the Citrus juices and their extracts, rising their potential use. However, their chemopreventive activity should be tested in clinical trials in order to strengthen the value of preclinical data presented in this systematic review. Indeed, despite the large body of evidence of pre-clinical studies showing Citrus juices anticancer effect, a current limitation for its antitumor employment is that clinical studies are only a few and their results were obtained through self-assessed tests on patients.

\section{CONCLUSION}

The present review has summarized the current status of the anticancer effects of Citrus juices and their extracts. Our

\section{REFERENCES}

Ahmed, I. S., Hassan, M. A., and Kondo, T. (2015). Effect of lyophilized grapefruit juice on P-glycoprotein-mediated drug transport in vitro and in vivo. Drug Dev. Ind. Pharm. 41,375-381. doi: 10.3109/03639045.2013.866141

Aibinu, I., Adenipekun, T., Adelowotan, T., Ogunsanya, T., and Odugbemi, T. (2006). Evaluation of the antimicrobial properties of different parts of Citrus aurantifolia (lime fruit) as used locally. Afr. J. Tradit. Complement. Altern. Med. 4, 185-190.

Amin, A. R., Kucuk, O., Khuri, F. R., and Shin, D. M. (2009). Perspectives for cancer prevention with natural compounds. J. Clin. Oncol. 27, 2712-2725. doi: 10.1200/JCO.2008.20.6235

Balkwill, F., and Mantovani, A. (2001). Inflammation and cancer: back to Virchow? Lancet 357, 539-545. doi: 10.1016/S0140-6736(00)04046-0

Barrett, H. C., and Rhodes, A. M. (1976). A numerical taxonomic study of affinity relationships in cultivated Citrus and its close relatives. Syst. Bot. 1, 105-136. doi: $10.2307 / 2418763$

Buscemi, S., Rosafio, G., Arcoleo, G., Mattina, A., Canino, B., Montana, M., et al. (2012). Effects of red orange juice intake on endothelial function and inflammatory markers in adult subjects with increased cardiovascular risk. Am. J. Clin. Nutr. 95, 1089-1095. doi: 10.3945/ajcn.111.031088

Camarda, L., Di Stefano, V., Del Bosco, S. F., and Schillaci, D. (2007). Antiproliferative activity of Citrus juices and HPLC evaluation of their flavonoid composition. Fitoterapia 78, 426-429. doi: $10.1016 /$ j.fitote.2007.02.020

Celano, M., Maggisano, V., De Rose, R. F., Bulotta, S., Maiuolo, J., Navarra, M., et al. (2015). Flavonoid fraction of Citrus reticulata juice reduces proliferation and migration of anaplastic thyroid carcinoma cells. Nutr. Cancer 67, 1183-1190. doi: 10.1080/01635581.2015.1073760

Celia, C., Trapasso, E., Locatelli, M., Navarra, M., Ventura, C. A., Wolfram, J., et al. (2013). Anticancer activity of liposomal bergamot essential oil (BEO) on human neuroblastoma cells. Colloids Surf. B Biointerfaces 112, 548-553. doi: 10.1016/j.colsurfb.2013.09.017

Cirmi, S., Bisignano, C., Mandalari, G., and Navarra, M. (2016a). Anti-infective potential of Citrus bergamia Risso et Poiteau (bergamot) derivatives: a systematic review. Phytother. Res. 30, 1404-1411. doi: 10.1002/ptr.5646

Cirmi, S., Ferlazzo, N., Lombardo, G. E., Maugeri, A., Calapai, G., Gangemi, S., et al. (2016b). Chemopreventive agents and inhibitors of cancer hallmarks: may Citrus offer new perspectives? Nutrients 8:e698. doi: 10.3390/nu8110698

Cirmi, S., Ferlazzo, N., Lombardo, G. E., Ventura-Spagnolo, E., Gangemi, S., Calapai, G., et al. (2016c). Neurodegenerative diseases: might Citrus study highlights the importance of Citrus juices and their extracts in a multitargeted-pharmacological strategy, suggesting their role in the prevention of cancer as well as their possible use as co-adjuvants in modern oncological therapies. However, further experimental and clinical studies are needed to exploit the beneficial aspects of these juices and their extracts in full.

\section{AUTHOR CONTRIBUTIONS}

SC: performed the systematic literature searching, the data extraction and helped in drafting the paper; AM: carried out the data extraction and contributed in writing the paper; NF: participated in the creation of the paper; US, GC, and SG: critically revised the paper; $\mathrm{MN}$ : conceived and designed the study, performed the systematic research and the data extraction, as well as drafted the paper. All authors read and approved the final manuscript.

flavonoids play a protective role? Molecules 21:e1312. doi: 10.3390/molecules 21 101312

Citraro, R., Navarra, M., Leo, A., Donato Di Paola, E., Santangelo, E., Lippiello, P., et al. (2016). The anticonvulsant activity of a flavonoid-rich extract from orange juice involves both NMDA and GABA-benzodiazepine receptor complexes. Molecules 21:e1261. doi: 10.3390/molecules21091261

Clere, N., Faure, S., Martinez, M. C., and Andriantsitohaina, R. (2011). Anticancer properties of flavonoids: roles in various stages of carcinogenesis. Cardiovasc. Hematol. Agents Med. Chem. 9, 62-77. doi: 10.2174/187152511796196498

Constans, J., Bennetau-Pelissero, C., Martin, J. F., Rock, E., Mazur, A., Bedel, A., et al. (2015). Marked antioxidant effect of orange juice intake and its phytomicronutrients in a preliminary randomized crossover trial on mild hypercholesterolemic men. Clin. Nutr. 34, 1093-1100. doi: 10.1016/j.clnu.2014.12.016

Corasaniti, M. T., Maiuolo, J., Maida, S., Fratto, V., Navarra, M., Russo, R., et al. (2007). Cell signaling pathways in the mechanisms of neuroprotection afforded by bergamot essential oil against NMDA-induced cell death in vitro. Br. J. Pharmacol. 151, 518-529. doi: 10.1038/sj.bjp.0707237

Costa, R., Dugo, P., Navarra, M., Raymo, V., Dugo, G., and Mondello, L. (2010). Study on the chemical composition variability of some processed bergamot (Citrus bergamia) essential oils. Flav. Frag. J. 25, 4-12. doi: 10.1002/ffj.1949

Crawford, S. (2014). Anti-inflammatory/antioxidant use in long-term maintenance cancer therapy: a new therapeutic approach to disease progression and recurrence. Ther. Adv. Med. Oncol. 6, 52-68. doi: $10.1177 / 1758834014521111$

Curro, M., Risitano, R., Ferlazzo, N., Cirmi, S., Gangemi, C., Caccamo, D., et al. (2016). Citrus bergamia juice extract attenuates beta-amyloid-induced proinflammatory activation of THP-1 cells through MAPK and AP-1 pathways. Sci. Rep. 6:20809. doi: 10.1038/srep20809

de la Garza, A. L., Etxeberria, U., Haslberger, A., Aumueller, E., Martinez, J. A., and Milagro, F. I. (2015). Helichrysum and grapefruit extracts boost weight loss in overweight rats reducing inflammation. J. Med. Food 18, 890-898. doi: 10.1089/jmf.2014.0088

Delle Monache, S., Sanita, P., Trapasso, E., Ursino, M. R., Dugo, P., Russo, M., et al. (2013). Mechanisms underlying the anti-tumoral effects of Citrus Bergamia juice. PLoS ONE 8:e61484. doi: 10.1371/journal.pone.0061484

de Moraes, A. P., dos Santos Soares Filho, W., and Guerra, M. (2007). Karyotype diversity and the origin of grapefruit. Chromosome Res. 15, 115-121. doi: 10.1007/s10577-006-1101-2

Dourado, G. K., Stanilka, J. M., Percival, S. S., and Cesar, T. B. (2015). Chemopreventive actions of blond and red-fleshed sweet orange juice on 
the Loucy Leukemia cell line. Asian Pac. J. Cancer Prev. 16, 6491-6499. doi: 10.7314/APJCP.2015.16.15.6491

Duarte, A., Fernandes, J., Bernardes, J., and Miguel, G. (2016). Citrus as a component of the Mediterranean diet. J. Spat. Org. Dyn. 4, 289-304.

Efferth, T., and Koch, E. (2011). Complex interactions between phytochemicals. The multi-target therapeutic concept of phytotherapy. Curr. Drug Targets 12, 122-132. doi: 10.2174/138945011793591626

Entezari, M., Majd, A., Falahian, F., Mehrabian, S., Hashemi, M., and Lajimi, A. A. (2009). Antimutagenicity and anticancer effects of Citrus Medica fruit juice. Acta Med. Iran. 47, 373-377.

Ferlazzo, N., Cirmi, S., Calapai, G., Ventura-Spagnolo, E., Gangemi, S., and Navarra, M. (2016a). Anti-inflammatory activity of citrus bergamia derivatives: where do we stand? Molecules 21:e1273. doi: 10.3390/molecules21101273

Ferlazzo, N., Cirmi, S., Russo, M., Trapasso, E., Ursino, M. R., Lombardo, G. E., et al. (2016b). NF-kappaB mediates the antiproliferative and proapoptotic effects of bergamot juice in HepG2 cells. Life Sci. 146, 81-91. doi: 10.1016/j.lfs.2015.12.040

Ferlazzo, N., Visalli, G., Cirmi, S., Lombardo, G. E., Lagana, P., Di Pietro, A., et al. (2016c). Natural iron chelators: protective role in A549 cells of flavonoids-rich extracts of Citrus juices in $\mathrm{Fe}(3+)$-induced oxidative stress. Environ. Toxicol. Pharmacol. 43, 248-256. doi: 10.1016/j.etap.2016.03.005

Ferlazzo, N., Visalli, G., Smeriglio, A., Cirmi, S., Lombardo, G. E., Campiglia, P., et al. (2015). Flavonoid fraction of orange and bergamot juices protect human lung epithelial cells from hydrogen peroxide-induced oxidative stress. Evid. Based Complement. Altern. Med. 2015:957031. doi: 10.1155/2015/957031

Fernandez-Bedmar, Z., Anter, J., de La Cruz-Ares, S., Munoz-Serrano, A., AlonsoMoraga, A., and Perez-Guisado, J. (2011). Role of citrus juices and distinctive components in the modulation of degenerative processes: genotoxicity, antigenotoxicity, cytotoxicity, and longevity in Drosophila. J. Toxicol. Environ. Health 74, 1052-1066. doi: 10.1080/15287394.2011.582306

Ferrão, J. E. M. (1979). Anais do Instituto Superior de Agronomia. Lisbon: Instituto Superior de Agronomia.

Filocamo, A., Bisignano, C., Ferlazzo, N., Cirmi, S., Mandalari, G., and Navarra, M. (2015). In vitro effect of bergamot (Citrus bergamia) juice against cagA-positive and-negative clinical isolates of Helicobacter pylori. BMC Complement. Altern. Med. 15:256. doi: 10.1186/s12906-015-0769-2

Fusco, R., Cirmi, S., Gugliandolo, E., Di Paola, R., Cuzzocrea, S., and Navarra, M. (2017). A flavonoid-rich extract of orange juice reduced oxidative stress in an experimental model of inflammatory bowel disease. J. Funct. Foods 30, 168-178. doi: 10.1016/j.jff.2016.12.038

Garcia-Lor, A., Curk, F., Snoussi-Trifa, H., Morillon, R., Ancillo, G., Luro, F., et al. (2013). A nuclear phylogenetic analysis: SNPs, indels and SSRs deliver new insights into the relationships in the 'true citrus fruit trees' group (Citrinae, Rutaceae) and the origin of cultivated species. Ann. Bot. 111, 1-19. doi: $10.1093 / \mathrm{aob} / \mathrm{mcs} 227$

Gharagozloo, M., Doroudchi, M., and Ghaderi, A. (2002). Effects of Citrus aurantifolia concentrated extract on the spontaneous proliferation of MDAMB-453 and RPMI-8866 tumor cell lines. Phytomedicine 9, 475-477. doi: 10.1078/09447110260571751

Giacosa, A., Barale, R., Bavaresco, L., Gatenby, P., Gerbi, V., Janssens, J., et al. (2013). Cancer prevention in Europe: the Mediterranean diet as a protective choice. Eur. J. Cancer Prev. 22, 90-95. doi: 10.1097/CEJ.0b013e328354d2d7

Gullett, N. P., Ruhul Amin, A. R., Bayraktar, S., Pezzuto, J. M., Shin, D. M., Khuri, F. R., et al. (2010). Cancer prevention with natural compounds. Semin. Oncol. 37, 258-281. doi: 10.1053/j.seminoncol.2010.06.014

Impellizzeri, D., Bruschetta, G., Di Paola, R., Ahmad, A., Campolo, M., Cuzzocrea, S., et al. (2015). The anti-inflammatory and antioxidant effects of bergamot juice extract (BJe) in an experimental model of inflammatory bowel disease. Clin. Nutr. 34, 1146-1154. doi: 10.1016/j.clnu.2014. 11.012

Impellizzeri, D., Cordaro, M., Campolo, M., Gugliandolo, E., Esposito, E., Benedetto, F., et al. (2016). Anti-inflammatory and antioxidant effects of flavonoid-rich fraction of Bergamot Juice (BJe) in a mouse model of intestinal ischemia/reperfusion injury. Front. Pharmacol. 7:203. doi: 10.3389/fphar.2016.00203

Jansen, R. J., Robinson, D. P., Stolzenberg-Solomon, R. Z., Bamlet, W. R., de Andrade, M., Oberg, A. L., et al. (2011). Fruit and vegetable consumption is inversely associated with having pancreatic cancer. Cancer Causes Control 22, 1613-1625. doi: 10.1007/s10552-011-9838-0

Kawaii, S., Tomono, Y., Katase, E., Ogawa, K., and Yano, M. (1999). Antiproliferative effects of the readily extractable fractions prepared from various citrus juices on several cancer cell lines. J. Agric. Food Chem. 47, 2509-2512. doi: 10.1021/jf9812228

Khan, M., Al-Yahyai, R., and Al-Said, F. (2017). The Lime: Botany, Production and Uses. Wallingford: CABI.

Kohno, H., Taima, M., Sumida, T., Azuma, Y., Ogawa, H., and Tanaka, T. (2001). Inhibitory effect of mandarin juice rich in beta-cryptoxanthin and hesperidin on 4-(methylnitrosamino)-1-(3-pyridyl)-1-butanoneinduced pulmonary tumorigenesis in mice. Cancer Lett. 174, 141-150. doi: 10.1016/S0304-3835(01)00713-3

Kozlowska, A., and Szostak-Wegierek, D. (2014). Flavonoids-food sources and health benefits. Rocz. Panstw. Zakl. Hig. 65, 79-85.

Liberati, A., Altman, D. G., Tetzlaff, J., Mulrow, C., Gotzsche, P. C., Ioannidis, J. P., et al. (2009). The PRISMA statement for reporting systematic reviews and meta-analyses of studies that evaluate health care interventions: explanation and elaboration. PLoS Med. 6:e1000100. doi: 10.1371/journal.pmed.1000100

Liu, R. H. (2004). Potential synergy of phytochemicals in cancer prevention: mechanism of action. J. Nutr. 134, 3479S-3485S.

Lv, X., Zhao, S., Ning, Z., Zeng, H., Shu, Y., Tao, O., et al. (2015). Citrus fruits as a treasure trove of active natural metabolites that potentially provide benefits for human health. Chem. Cent. J. 9:68. doi: 10.1186/s13065-015-0145-9

Mabberley, D. J. (1997). A classification for edible Citrus (Rutaceae). Telopea 7, 167-172. doi: 10.7751/telopea19971007

Mabberley, D. J. (2009). Mabberley's Plant-Book: a Portable Dictionary of Plants, their Classification and Uses. Cambridge: Cambridge University Press.

Madrigal-Bujaidar, E., Martino Roaro, L., Garcia-Aguirre, K., GarciaMedina, S., and Alvarez-Gonzalez, I. (2013). Grapefruit juice suppresses azoxymethane-induced colon aberrant crypt formation and induces antioxidant capacity in mice. Asian Pac. J. Cancer Prev. 14, 6851-6856. doi: 10.7314/APJCP.2013.14.11.6851

Mandalari, G., Bisignano, C., Cirmi, S., and Navarra, M. (2017). Effectiveness of Citrus Fruits on Helicobacter pylori. Evid. Based Complement. Altern. Med. 2017:8379262. doi: 10.1155/2017/8379262

Mannucci, C., Navarra, M., Calapai, F., Squeri, R., Gangemi, S., and Calapai, G. (2017). Clinical pharmacology of Citrus bergamia: a systematic review. Phytother. Res. 31, 27-39. doi: 10.1002/ptr.5734

Marino, A., Paterniti, I., Cordaro, M., Morabito, R., Campolo, M., Navarra, M., et al. (2015). Role of natural antioxidants and potential use of bergamot in treating rheumatoid arthritis. PharmaNutrition 3, 53-59. doi: 10.1016/j.phanu.2015.03.002

Maserejian, N. N., Giovannucci, E., Rosner, B., Zavras, A., and Joshipura, K. (2006). Prospective study of fruits and vegetables and risk of oral premalignant lesions in men. Am. J. Epidemiol. 164, 556-566. doi: 10.1093/aje/kwj233

Micali, S., Isgro, G., Bianchi, G., Miceli, N., Calapai, G., and Navarra, M. (2014). Cranberry and recurrent cystitis: more than marketing? Crit. Rev. Food Sci. Nutr. 54, 1063-1075. doi: 10.1080/10408398.2011.625574

Miyagi, Y., Om, A. S., Chee, K. M., and Bennink, M. R. (2000). Inhibition of azoxymethane-induced colon cancer by orange juice. Nutr. Cancer 36, 224-229. doi: 10.1207/S15327914NC3602_12

Miyata, M., Takano, H., Takahashi, K., Sasaki, Y. F., and Yamazoe, Y. (2002). Suppression of 2-amino-1-methyl-6-phenylimidazo[4,5-b]pyridine-induced DNA damage in rat colon after grapefruit juice intake. Cancer Lett. 183, 17-22. doi: 10.1016/S0304-3835(02)00109-X

Mollace, V., Sacco, I., Janda, E., Malara, C., Ventrice, D., Colica, C., et al. (2011). Hypolipemic and hypoglycaemic activity of bergamot polyphenols: from animal models to human studies. Fitoterapia 82, 309-316. doi: 10.1016/j.fitote.2010.10.014

Navarra, M., Ferlazzo, N., Cirmi, S., Trapasso, E., Bramanti, P., Lombardo, G. E., et al. (2015a). Effects of bergamot essential oil and its extractive fractions on SHSY5Y human neuroblastoma cell growth. J. Pharm. Pharmacol. 67, 1042-1053. doi: $10.1111 /$ jphp.12403

Navarra, M., Mannucci, C., Delbo, M., and Calapai, G. (2015b). Citrus bergamia essential oil: from basic research to clinical application. Front. Pharmacol. 6:36. doi: 10.3389/fphar.2015.00036 
Navarra, M., Ursino, M. R., Ferlazzo, N., Russo, M., Schumacher, U., and Valentiner, U. (2014). Effect of Citrus bergamia juice on human neuroblastoma cells in vitro and in metastatic xenograft models. Fitoterapia 95, 83-92. doi: 10.1016/j.fitote.2014.02.009

Navarro, P., Perez-Lopez, A. J., Mercader, M. T., Carbonell-Barrachina, A. A., and Gabaldon, J. A. (2011). Antioxidant activity, color, carotenoids composition, minerals, vitamin $\mathrm{C}$ and sensory quality of organic and conventional mandarin juice, cv. Orogrande. Food Sci. Technol. Int. 17, 241-248. doi: 10.1177/1082013210382334

Nicolosi, E., Deng, Z. N., Gentile, A., La Malfa, S., Continella, G., and Tribulato, E. (2000). Citrus phylogeny and genetic origin of important species as investigated by molecular markers. Theor. Appl. Genet. 100, 1155-1166. doi: $10.1007 / \mathrm{s} 001220051419$

Oikeh, E. I., Omoregie, E. S., Oviasogie, F. E., and Oriakhi, K. (2016). Phytochemical, antimicrobial, and antioxidant activities of different citrus juice concentrates. Food Sci. Nutr. 4, 103-109. doi: 10.1002/fsn3.268

Ollitrault, P., Terol, J., Garcia-Lor, A., Berard, A., Chauveau, A., Froelicher, Y., et al. (2012). SNP mining in C. clementina BAC end sequences; transferability in the Citrus genus (Rutaceae), phylogenetic inferences and perspectives for genetic mapping. BMC Genomics 13:13. doi: 10.1186/1471-2164-13-13

Paterniti, I., Cordaro, M., Campolo, M., Siracusa, R., Cornelius, C., Navarra, M., et al. (2014). Neuroprotection by association of palmitoylethanolamide with luteolin in experimental Alzheimer's disease models: the control of neuroinflammation. CNS Neurol. Disord. Drug Targets 13, 1530-1541. doi: $10.2174 / 1871527313666140806124322$

Patil, J. R., Chidambara Murthy, K. N., Jayaprakasha, G. K., Chetti, M. B., and Patil, B. S. (2009). Bioactive compounds from Mexican lime (Citrus aurantifolia) juice induce apoptosis in human pancreatic cells. J. Agric. Food Chem. 57, 10933-10942. doi: 10.1021/jf901718u

Raimondo, S., Naselli, F., Fontana, S., Monteleone, F., Lo Dico, A., Saieva, L., et al. (2015). Citrus limon-derived nanovesicles inhibit cancer cell proliferation and suppress CML xenograft growth by inducing TRAIL-mediated cell death. Oncotarget 6, 19514-19527. doi: 10.18632/oncotarget.4004

Rapisarda, A., and Germanò, M. P. (2013). "Citrus bergamia risso and poiteau botanical classification, morphology and anatomy," in Citrus bergamia: Bergamot and its Derivatives, eds G. Dugo and I. Bonaccorsi (Boca Raton, FL: CCR Press), 9-11.

Ravishankar, D., Rajora, A. K., Greco, F., and Osborn, H. M. (2013). Flavonoids as prospective compounds for anti-cancer therapy. Int. J. Biochem. Cell Biol. 45, 2821-2831. doi: 10.1016/j.biocel.2013.10.004

Risitano, R., Curro, M., Cirmi, S., Ferlazzo, N., Campiglia, P., Caccamo, D., et al. (2014). Flavonoid fraction of Bergamot juice reduces LPS-induced inflammatory response through SIRT1-mediated NF-kappaB inhibition in THP-1 monocytes. PLoS ONE 9:e107431. doi: 10.1371/journal.pone.0107431

Scora, R. W. (1988). "Biochemistry, taxonomy and evolution of modern cultivated citrus," Citriculture Tel Aviv: Proceedings of the International Society of Citriculture, eds R. Goren and K. Mendel (Tel Aviv), 277-289.

Semba, R. D., Ferrucci, L., Bartali, B., Urpi-Sarda, M., Zamora-Ros, R., Sun, K., et al. (2014). Resveratrol levels and all-cause mortality in older community-dwelling adults. JAMA Intern. Med. 174, 1077-1084. doi: 10.1001/jamainternmed.2014.1582

So, F. V., Guthrie, N., Chambers, A. F., Moussa, M., and Carroll, K. K. (1996). Inhibition of human breast cancer cell proliferation and delay of mammary tumorigenesis by flavonoids and citrus juices. Nutr. Cancer 26, 167-181. doi: $10.1080 / 01635589609514473$

Surh, Y. J. (2003). Cancer chemoprevention with dietary phytochemicals. Nat. Rev. Cancer 3, 768-780. doi: 10.1038/nrc1189

Swingle, W. T., and Reece, P. C. (1967). "The botany of citrus and its wild relatives of the orange subfamily," in The Citrus Industry. 2nd Edn. Vol. 1, History, World
Distribution, Botany, and Varieties, eds W. Reuther, H. J. Webber, and L. D. Batchelor (Berkeley, CA: University of California), 190-40.

Tacklind, J., Macdonald, R., Rutks, I., Stanke, J. U., and Wilt, T. J. (2012). Serenoa repens for benign prostatic hyperplasia. Cochrane Database Syst. Rev. 12:CD001423. doi: 10.1002/14651858.CD001423

Tanaka, C. (1954). Species Problem in Citrus; a Critical Study of Wild and Cultivated Units of Citrus, Based Upon Field Studies in their Native Homes, Vol. 9. Tokyo: Japanese Society for the Promotion of Science.

Tanaka, T. (1977). Fundamental discussion of citrus classification. Study Citrologia $14,1-6$.

Tanaka, T., Kohno, H., Murakami, M., Shimada, R., Kagami, S., Sumida, T., et al. (2000). Suppression of azoxymethane-induced colon carcinogenesis in male F344 rats by mandarin juices rich in beta-cryptoxanthin and hesperidin. Int. J. Cancer 88, 146-150. doi: 10.1002/1097-0215(20001001)88:1<146::AID-IJC23>3.0.CO;2-I

Tanaka, T., Tanaka, T., Tanaka, M., and Kuno, T. (2012). Cancer chemoprevention by citrus pulp and juices containing high amounts of beta-cryptoxanthin and hesperidin. J. Biomed. Biotechnol. 2012:516981. doi: 10.1155/2012/516981

Tarozzi, A., Hrelia, S., Angeloni, C., Morroni, F., Biagi, P., Guardigli, M., et al. (2006). Antioxidant effectiveness of organically and non-organically grown red oranges in cell culture systems. Eur. J. Nutr. 45, 152-158. doi: 10.1007/s00394-005-0575-6

Tomasetti, C., and Vogelstein, B. (2015). Cancer etiology. Variation in cancer risk among tissues can be explained by the number of stem cell divisions. Science 347, 78-81. doi: 10.1126/science. 1260825

Toth, P. P., Patti, A. M., Nikolic, D., Giglio, R. V., Castellino, G., Biancucci, T., et al. (2015). Bergamot reduces plasma lipids, atherogenic small dense LDL, and Subclinical atherosclerosis in subjects with moderate hypercholesterolemia: a 6 months prospective study. Front. Pharmacol. 6:299. doi: 10.3389/fphar.2015.00299

Tounsi, M. S., Wannes, W. A., Ouerghemmi, I., Jegham, S., Ben Njima, Y., Hamdaoui, G., et al. (2011). Juice components and antioxidant capacity of four Tunisian Citrus varieties. J. Sci. Food Agric. 91, 142-151. doi: 10.1002/jsfa. 4164

Ullah, M. F., and Khan, M. W. (2008). Food as medicine: potential therapeutic tendencies of plant derived polyphenolic compounds. Asian Pac. J. Cancer Prev. 9, 187-195.

Visalli, G., Ferlazzo, N., Cirmi, S., Campiglia, P., Gangemi, S., Di Pietro, A., et al. (2014). Bergamot juice extract inhibits proliferation by inducing apoptosis in human colon cancer cells. Anticancer. Agents Med. Chem. 14, 1402-1413. doi: 10.2174/1871520614666140829120530

Yang, J., Lee, D., Afaisen, S., and Gadi, R. (2013). Inactivation by lemon juice of Escherichia coli O157:H7, Salmonella Enteritidis, and Listeria monocytogenes in beef marinating for the ethnic food kelaguen. Int. J. Food Microbiol. 160, 353-359. doi: 10.1016/j.ijfoodmicro.2012.11.009

Zaragoza, S. (1991). “Antecedentes Históricos," in Historia de la Naranja, ed V. Abad (Valencia: Levante/Genaralitat Valenciana).

Conflict of Interest Statement: The authors declare that the research was conducted in the absence of any commercial or financial relationships that could be construed as a potential conflict of interest.

Copyright (c) 2017 Cirmi, Maugeri, Ferlazzo, Gangemi, Calapai, Schumacher and Navarra. This is an open-access article distributed under the terms of the Creative Commons Attribution License (CC BY). The use, distribution or reproduction in other forums is permitted, provided the original author(s) or licensor are credited and that the original publication in this journal is cited, in accordance with accepted academic practice. No use, distribution or reproduction is permitted which does not comply with these terms. 